\title{
PENGARUH PEMBERIAN INSENTIF TERHADAP KINERJA KEPALA SEKOLAH DASAR SE-KOTA DENPASAR
}

\author{
Putu Ledyari Noviyanti, Anak Agung Inten Paraniti \\ Program Studi Pendidikan Matematika FKIP Unmas Denpasar \\ email: ledyarinoviyanti@unmas.ac.id
}

\begin{abstract}
ABSTRAK
Pemerintah Daerah Kota Denpasar mengeluarkan kebijakan terkait pemberian tunjangan. Tunjangan yang diberikan berupa insentif tambahan bagi guru dan kepala sekolah khususnya sekolah dasar negeri di daerah Kota Denpasar. Pemberian insentif bertujuan agar kepala sekolah lebih maksimal dalam mengemban tugas atau beban kerja, serta mengoptimalkan potensi-potensi yang bisa dikembangkan di sekolah tersebut (baik dalam aspek prestasi guru dan siswa). Berdasarkan latar belakang tersebut dilakukan penelitian yang bertujuan untuk mengetahui pengaruh pemberian insentif terhadap kinerja kepala sekolah dasar Se-Kota Denpasar.Teknik analisis yang digunakan dalam penelitian ini adalah regresi linear sederhana. Berdasarkan data yang dianalisis diperoleh 1) variabilitas variabel dependen (kinerja kepala sekolah dasar) yang dapat dijelaskan oleh variabilitas variabel independen (pemberian insentif) sebesar 15,5\% dan sisanya sebesar 84,5\% dijelaskan oleh variabel lain yang tidak dimasukkan dalam model regresi, 2) pemberian insentif kepala sekolah berpengaruh positif secara signifikan terhadap kinerja kepala sekolah dasar Se-Kota Denpasar.
\end{abstract}

Kata Kunci: Insentif, Kinerja Kepala Sekolah Dasar, Kota Denpasar

\section{ABSTRACT}

The Regional Government of Denpasar City issued a policy regarding the provision of incentives. The incentives provided are in the form of additional incentives for teachers and headmaster, especially for public elementary schools in the Denpasar City area. The provision of incentives aims to make the headmaster more maximal in carrying out assigment or workloads, and to optimize the potentials that can be developed in the school (both in aspects of teacher and student achievement). Based on this background, a study was conducted which aimed to determine the effect of giving incentives on the performance of elementary school headmaster throughout Denpasar. The analysis technique used in this study is simple linear regression. Based on the data analyzed, it was obtained 1) the variability of the dependent variable (primary school principal's performance) which can be explained by the variability of the independent variable (incentive giving) of $15.5 \%$ and the remaining $84.5 \%$ explained by other variables not included in the regression model and 2) giving headmaster incentives has a significant positive effect on the performance of elementary school principals throughout Denpasar.

Keywords: Incentives, Performance of Elementary School Principals, Denpasar City

\section{PENDAHULUAN}

Pendidikan memiliki peran yang sangat penting dalam perkembangan maupun kemajuan suatu Negara. Seluruh negara memberikan perhatian secara khusus terhadap pendidikan saat ini. Salah satunya adalah negara kita, Negara Republik Indonesia. Berbagai kebijakan telah dilakukan oleh pemerintah guna meningkatkan kualitas pendidikan menjadi lebih baik. Kebijakan-kebijakan tersebut diarahkan ke masing-masing 
bagian yang berbeda. Contohnya pengembangan kurikulum terbaru, yaitu kurikulum 2013. Pengembangan kurikulum ini sebagai upaya meningkatkan kualitas pembelajaran. Kebijakan yang lain juga menyasar tenaga pendidik,yaitu guru. Kebijakan yang dibuat seperti pemberian tunjangan diluar gaji pokok. Tunjangan yang kita ketahui adalah tunjangan sertifikasi guru.

Searah dengan kebijakan pusat yang memberikan tunjangan sertifikasi guru kepada guru yang telah profesional atau layak mendapat tunjangan ini, Pemerintah Daerah Kota Denpasar juga mengeluarkan kebijakan terkait pemberian tunjangan. Tunjangan yang diberikan ini berupa insentif tambahan bagi guru dan kepala sekolah di daerah Kota Denpasar. Besarnya insentif yang diberikan baik itu kepada guru dan kepala sekolah berbeda nominalnya. Hal ini dikarenakan kepala sekolah memiliki tanggung jawab atau beban kerja yang lebih dibandingkan guru. Kelebihan insentif yang didapat oleh kepala sekolah merupakan sebuah apresiasi dari Pemerintah Daerah Kota Denpasar atas dedikasi serta kerja keras masing-masing kepala sekolah untuk memimpin sekolahnya.

Pemerintah Daerah Kota Denpasar mengharapkan, dengan pemberian insentif kepada kepala sekolah ini, kepala sekolah lebih maksimal dalam mengemban tugas atau beban kerja sebagai kepala sekolah, serta mengoptimalkan potensi-potensi yang bisa dikembangkan di sekolah tersebut (baik dalam aspek prestasi guru dan siswa). Hal ini sangat wajar, dikarenakan tuntutan pekerjaan baik dari atasan dalam hal ini Dinas Pendidikan Kota/Kabupaten, Provinsi dan bahkan
Nasional sangatlah banyak serta memerlukan pemikiran-pemikiran yang mendalam dari kepala sekolah. Seperti keikutsertaan kepala sekolah dalam seminar-seminar yang diadakan lembagalembaga pendidikan.

Dengan pemberian insentif kepada kepala sekolah diharapkan nantinya secara mendasar membantu meningkatkan kualitas pendidikan secara global. Pemberian insentif ini diharapkan memberikan dampak positif secara materiil kepada kepala sekolah. Dalam hal optimalisasi penggunaan teknologi dalam kegiatan kepemimpinan di sekolah, partisipasi aktif dalam semua kegiatan yang berhubungan dengan pendidikan.

Senada dengan hal diatas, berikut beberapa penelitian yang telah dilakukan sebelumnya yang menunjukkan adanya pengaruh pemberian tunjangan/insentif pada kinerja tenaga pendidik. Rochmat (2013) dalam penelitian "Pengaruh Insentif Terhadap Motivasi Dan Kinerja" mengungkapkan insentif materiil dan insentif non materiil mempunyai pengaruh langsung terhadap motivasi kerja dan kinerja karyawan, serta pengaruh tidak langsung terhadap kinerja karyawan. Selain itu, Setyono (2009) dalam penelitiannya yang berjudul "Pengaruh Kompetensi Guru, Insentif dan Lingkungan Kerja Fisik Terhadap Kinerja Guru SMA Negeri 1 Patimuan Kabupaten Cilacap" mengungkapkan beberapa hal yaitu :1) Kompetensi guru mempunyai pengaruh yang positif terhadap kinerja guru. Artinya jika kompetensi guru ditingkatkan, maka akan meningkatkan kinerja guru SMA Negeri 1 Patimuan Kabupaten Cilacap. 2) Insentif mempunyai pengaruh yang positif terhadap kinerja guru. Artinya jika insentif guru ditingkatkan, maka akan meningkatkan 
kinerja guru SMA Negeri 1 Patimuan Kabupaten Cilacap. 3) Lingkungan kerja fisik guru mempunyai pengaruh yang positif terhadap kinerja guru SMA Negeri 1 Patimuan Kabupaten Cilacap. Artinya jika lingkungan kerja fisik ditingkatkan menjadi lebih baik, maka akan meningkatkan kinerja guru SMA Negeri 1

Patimuan Kabupaten Cilacap. 4) Kompetensi guru merupakan faktor yang mempunyai pengaruh paling besar terhadap kinerja guru SMA Negeri 1 Patimuan Kabupaten Cilacap.

Berdasarkan beberapa penelitian sebelumnya, maka peneliti melakukan penelitian yang berjudul "Pengaruh Pemberian Insentif Terhadap Kinerja Kepala Sekolah Se-Kota Denpasar". Adapun masalah dalam penelitian ini adalah apakah terdapat pengaruh yang signifikan dalam pemberian insentif terhadap kinerja kepala sekolah Se-Kota Denpasar?. Serta, tujuan penelitian ini adalah untuk mengetahui signifikansi pengaruh pemberian insentif terhadap kinerja kepala sekolah Se-Kota Denpasar. Insentif sebagai sarana motivasi yang mendorong para pegawai untuk bekerja dengan kemampuan optimal, yang dimaksudkan sebagai pendapatan ekstra diluar gaji atau upah yang telah ditentukan. Pemberian insentif dimaksudkan agar dapat memenuhi kebutuhan hidup para karyawan atau pekerja serta keluarga mereka. Istilah sistem insentif pada umumnya digunakan untuk menggambarkan rencana pembayaran upah yang dikaitan secara langsung maupun tidak langsung dengan berbagai standar kinerja karyawan. Insentif dapat dirumuskan sebagai balas jasa yang diberikan oleh perusahaan atau lembaga guna memadai para karyawan yang memiliki prestasi kerja lebih dari standar kerja yang telah ditetapkan. Insentif merupakan suatu faktor pendorong bagi karyawan untuk bekerja lebih baik agar kinerja karyawan dapat meningkat.

Adapun pengertian insentif menurut Mangkunegara (2011:89), sebagai berikut: Insentif kerja adalah suatu penghargaan dalam bentuk uang yang diberikan oleh pihak pemimpin organisasi kepada karyawan agar mereka bekerja dengan motivasi yang tinggi dan berprestasi dalam mencapai tujuan-tujuan organisasi atau dengan kata lain, insentif kerja merupakan pemberian uang di luar gaji yang dilakukan oleh pihak pemimpin organisasi sebagai pengakuan terhadap prestasi kerja dan kontribusi karyawan kepada organisasi.

Hal senada dikemukakan oleh Panggabean (2004:77), yang menyatakan bahwa "Insentif merupakan imbalan langsung yang dibayarkan kepada karyawan karena kinerjanya melebihi standar yang ditentukan. Dengan mengasumsikan bahwa uang dapat digunakan untuk mendorong karyawan bekerja lebih giat lagi, maka mereka yang produktif lebih menyukai gajinya dibayarkan berdasarkan hasil kerja.

Berdasarkan uraian pendapat para ahli di atas dapat penulis simpulkan, bahwa insentif merupakan salah satu bentuk rangsangan atau motivasi (berupa uang dan diluar gaji pokok) yang diberikan oleh perusahaan atau lembaga kepada karyawan, untuk mendorong semangat kerja para karyawan agar lebih produktif, dan meningkatkan kinerja untuk mencapai prestasi dalam pekerjaan. Dalam penelitian ini insentif yang dimaksudkan adalah salah satu bentuk rangsangan atau motivasi (berupa uang dan diluar gaji pokok) yang diberikan oleh Pemerintah Daerah Kota Denpasar kepada Kepala Sekolah sebagai 
upaya apresiasi atas kelebihan beban kerja yang ditanggung oleh kepala sekolah tersebut.

Indikator-indikator kinerja kepala sekolah yang digunakan dalam penelitian ini adalah : 1) mewujudkan proses pembelajaran yang efektif, 2) menerapkan system evaluasi yang efektif dan melakukan perbaikan secara berkelanjutan, 3) melakukan refleksi diri ke arah pembentukan karakter kepemimpinan sekolah yang kuat, 4) melaksanakan pengembangan staf yang kompeten dan berdedikasi tinggi, 5) menumbuhkan sikap responsif dan antisipatif terhadap kebutuhan, 6) menciptakan lingkungan sekolah yang aman dan tertib (Safe and Orderly), 7) menumbuhkan budaya mutu di lingkungan sekolah, 8) menumbuhkan harapan prestasi tinggi, 9) menumbuhkan kemauan untuk berubah, 10) melaksanakan Keterbukaan/Transparan Managemen Sekolah, 11) menetapkan secara jelas mewujudkan Visi dan Misi, 12) melaksanakan pengelolaan tenaga kependidikan secara efektif, 13) melaksanakan pengelolaan sumber belajar secara efektif, 14) melaksanakan pengelolaan kegiatan kesiswaan/ Ekstrakurikuler secara efektif, dan 15) mengembangkan kepemimpinan instruksional.

\section{METODOLOGI}

Populasi penelitian ini adalah seluruh kepala sekolah dasar Se-Kota Denpasar. Kota Denpasar memiliki 4 kecamatan yaitu, Kecamatan Denpasar Timur, Kecamatan Denpasar Barat, Kecamatan Denpasar Utara dan Kecamatan Denpasar Selatan. Dari empat kecamatan yang ada diambil 30 sampel yang mewakili kepala sekolah dari masing-masing kecamatan. Teknik penentuan sampel yang digunakan adalah random sampling. Variabel independen dalam penelitian ini adalah pemberian insentif dan variabel dependen dalam penelitian ini adalah kinerja kepala sekolah dasar.

Sebelum data dianalisis, terlebih dahulu dilakukan uji prasyarat penelitian yaitu uji validitas, uji homogenitas dan uji normalitas. Pengujian hipotesis untuk pengaruh insentif terhadap kinerja kepala sekolah dasar Se-Kota Denpasar menggunakan analisis regresi linear sederhana. Pengujian dengan analisis regresi linear sederhana dilakukan untuk menguji pengaruh satu variabel independen terhadap variabel dependen dengan menggunakan alat bantu SPSS 16.0.

\section{PEMBAHASAN}

Hasil

\section{Deskripsi Responden dan Statistik Deskriptif Penelitian}

Berdasarkan jenis kelamin, responden pria terdiri dari 19 responden dan responden wanita terdiri dari 11 responden. Berdasarkan jenjang pendidikan, responden dengan pendidikan terakhir Strata 1 (S1) terdiri dari 24 responden dan 6 responden dengan pendidikan terakhir Strata 2 (S2). Berdasarkan kisaran lama menjabat sebagai kepala sekolah antara 113 tahun.

\section{Uji Kualitas Data}

Hasil uji validitas menunjukkan bahwa keseluruhan indikator variabel yang digunakan dalam penelitian ini memiliki nilai Person Correlation yang lebih tinggi dari 0,5. Oleh karena itu dapat dikatakan bahwa semua indikator tersebut adalah valid

Hasil uji reliabilitas menunjukkan bahwa keseluruhan variabel memiliki nilai 
Cronbach's Alpha yaitu 0,741 untuk insentif dan 0,925 untuk kinerja dimana lebih tinggi dari 0,6. Dengan demikian dapat dikatakan bahwa keseluruhan pengukur variabel yang digunakan dalam penelitian adalah reliabel.

\section{Uji Asumsi Klasik}

Tabel 1.

Uji Normalitas

\begin{tabular}{|ll|l|}
\hline N & & Unstandardized Residual \\
\hline Normal Parameters ${ }^{\mathrm{a}}$ & Mean & .0000000 \\
& Std. Deviation & \\
Most Extreme Differences & Absolute & .34063881 \\
& Positive & .132 \\
Kolmogorov-Smirnov Z & Negative & .132 \\
Asymp. Sig. (2-tailed) & & -.093 \\
\hline a. Test distribution is Normal. & & .720 \\
\hline
\end{tabular}

Berdasarkantabel1 diatas,hasil uji tingkat signifikansi penelitian yaitu 0,05. normalitas menunjukkan bahwa nilai Oleh karena itu dapat disimpulkan bahwa Kolmogorov-Smirnov adalah sebesar data residualterdistribusisecaranormal. 0,720 dan tingkat signifikansi pada 0,677 . Tingkat signifikansi ini lebih besar dari

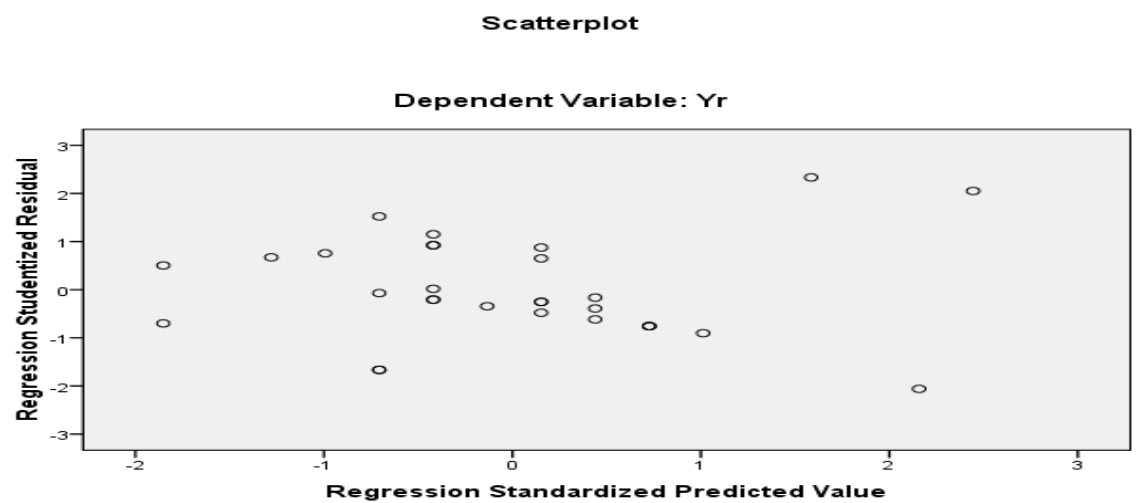

Gambar 1. Scatterplot

Hasil uji heterokedastisitas menunjukkan bahwa dari hasil ouput gambar 1 scatterplot, didapat titik menyebar di bawah serta diatas sumbu yang tidak memiliki pola teratur. Dengan demikian dapat disimpulkan variabel bebas diatas bersifat homoskedastisitas. 


\section{Uji Regresi Linier Berganda}

Tabel 2. Uji Regresi Linier Sederhana

\begin{tabular}{|c|c|c|c|c|c|}
\hline & & & Model Summary & & \\
\hline Model & $\mathrm{R}$ & R Square & Adjusted R Square & Std. Error of the Estimate & $\begin{array}{l}\text { Durbin- } \\
\text { Watson }\end{array}$ \\
\hline 1 & $.429^{\mathrm{a}}$ & .184 & .155 & .34667 & 2.061 \\
\hline
\end{tabular}

Berdasarkantabel

2, dapatdilihatbahwamodelregresiinimemi likinilaiAdjusted $\mathrm{R}^{2}$ sebesar0,155.

Haliniberartivariabilitasvariabeldependen yangdapatdijelaskanolehvariabilitasvariab elindependenadalahsebesar
15,5\%.Sedangkansisanyasebesar 84,5\%dijelaskanolehvariabellainyangtida kdimasukkandalammodelregresi.

Tabel 3. Uji Parsial

\begin{tabular}{|c|c|c|c|c|}
\hline \multirow{2}{*}{\multicolumn{2}{|c|}{ Model }} & Standardized Coefficients & \multirow[b]{2}{*}{$\mathrm{t}$} & \multirow[b]{2}{*}{ Sig. } \\
\hline & & Beta & & \\
\hline \multirow[t]{2}{*}{1} & (Constant) & & 2.306 & .029 \\
\hline & $\mathrm{Xr}$ & .429 & 2.512 & .018 \\
\hline
\end{tabular}

Arahkoefisienregresivariabeltingkat pemberian insentif terhadap kinerjakepala sekolah dasar adalahsebesar0,429denganarahpositif.Has ilpengujianpengaruh pemberian insentif terhadap kinerja kepela sekolah dasar tingkatsignifikansisebesar0,018.Tingkatsi gnifikansipenelitianlebihkecildaritingkatsi gnifikansisebesar0,05.Dengandemikianpe mberian insentif berpengaruhpositifterhadapkinerja kepala sekolah dasar secara signifikan.

Dari variabel independen yang digunakan yaitu pemberian insentif menunjukkan hubungan yang positifsignifikan terhadap variabel independen yaitu kinerja kepala sekolah dasar.

\section{KESIMPULAN}

Berdasarkan penelitian yang telah dilakukan, maka dapat disimpulkan bahwa:

1. Variabilitasvariabeldependen (kinerja kepala sekolah dasar)yangdapatdijelaskanolehvariabi litasvariabelindependen (pemberian insentif)sebesar $15,5 \%$ dan sisanya sebesar $84,5 \%$ dijelaskan oleh variabel lain yang tidak dimasukkan dalam model regresi.

2. Pemberian insentif kepala sekolah berpengaruhpositif secara signifikan terhadapkinerja kepala sekolah dasar Se-Kota Denpasar. 


\section{DAFTAR PUSTAKA}

Mangkunegara, A.A Anwar Prabu. 2011. Manajemen Sumber Daya Manusia. Bandung: Remaja RosdaKarya

Panggabean, Mutiara S. 2004. Manajemen Sumber Daya Manusia. Bogor: Ghalia Indonesia

Rochmat, Kurniya Budi . 2013. Pengaruh Insentif Terhadap Motivasi Dan Kinerja. Jurnal Administrasi Bisnis (JAB) Vol. 1 No. 1 April 2013

Setyono , Hendro. 2009. Pengaruh Kompetensi Guru, Insentif Dan Lingkungan Kerja Fisik Terhadap Kinerja Guru Sma Negeri 1 Patimuan Kabupaten Cilacap. Diakses dalam bentuk pdf tanggal 8 Juni 2018 